\title{
VISUALISASI KONSEP PERLAYANGAN GELOMBANG DENGAN MEMANFAATKAN SPREADSHEET EXCEL
}

\author{
1.Iryan Dwi Handayani, ${ }^{2 \cdot}$ Agus Margiantono, ${ }^{3}$ Fahrudin Ahmad \\ 1,2,3. Fakultas Teknik, Universitas Semarang, Jl. Soekarno Hatta Semarang \\ Email: iryandwi1201@gmail.com
}

\begin{abstract}
Abstrak - Perkembangan ilmu pengetahuan dan teknologi yang semakin maju telah menghasilkan berbagai macam peralatan canggih yang dapat menunjang terpenuhinya kebutuhan hidup. Oleh sebab itu diperlukan generasi penerus yang pandai dan kreatif. Hal ini yang menyebabkan kebutuhan pendidikan yang semakin tinggi dan permasalahannya semakin kompleks. Pembelajaran tentang gelombang sudah didapatkan sejak duduk di bangku SMP, tetapi pemahaman tentang hal ini masih kurang. Oleh karena itu, dengan memanfaatkan fasilitas-fasilitas yang diberikan komputer, perumusanperumusan gelombang elektromagnetik yang abstrak akan lebih mudah dipahami. Visualisasi dari grafiknya dapat memberikan kemudahan bagi mahasiswa untuk lebih memahami materi yang diberikan. Penelitian ini dilaksanakan dalam dua tahapan, tahapan yang pertama dimulai dari studi pustaka pendukung terutama yang berkaitan dengan superposisi gelombang. Langkah selanjutnya adalah menurunkan rumusan superposisi dua gelombang dengan variasi frekuensi, amplitudo, dan fase yang berbeda-beda. Tahapan kedua yang dilakukan hampir sama dengan tahapan pertama yaitu studi pustaka, namun cukup dengan memperoleh fungsi gelombang tunggal. Selanjutnya berdasarkan fungsi gelombang dengan variasi frekuensi, amplitudo, dan fase. Proses superposisi gelombang dilakukan dengan cara menjumlahkan data sintetik fungsi gelombang 1 dan 2, menghasilkan data sintetik fungsi gelombang hasil superposisi. Data sintetik ini kemudian divisualisasikan dalam bentuk grafik Penelitian ini menghasilkan visualisasi konsep perlayangan gelombang yang diungkapkan dalam grafik hubungan antara simpangan terhadap waktu dengan frekuensi berbeda, amplitudo dan beda fase yang berbeda.
\end{abstract}

Kata kunci : perlayangan gelombang, superposisi, spreadsheet

\section{PENDAhuluaN}

Perkembangan ilmu pengetahuan dan teknologi yang semakin maju telah menghasilkan berbagai macam peralatan canggih yang dapat menunjang terpenuhinya kebutuhan hidup. Negara indonesia merupakan negara yang terus berkembang, sehingga perlu terus belajar dan berusaha agar mampu bersaing dengan negara-negara lain yang berkembang lebih maju dalam segala hal. Oleh sebab itu diperlukan generasi penerus yang pandai dan kreatif. Hal ini yang menyebabkan kebutuhan pendidikan yang semakin tinggi dan permasalahannya semakin kompleks.

Pembelajaran tentang gelombang sudah didapatkan sejak duduk di bangku SMP, tetapi pemahaman tentang hal ini masih kurang khususnya perlayangan gelombang. Selama ini pemahaman konsep perlayangan gelombang hanya sebatas pada penjelasannya dalam buku ajar secara singkat, jarang kita lihat dalam bentuk lain, misalnya visualisasi secara langsung.

Sedangkan pada saat ini, komputer adalah suatu perangkat modern yang mempunyai banyak kelebihan, diantaranya adalah kemampuan numeriknya yang bagus, dapat memvisualisasikan grafik dan pengoperasiannya tidak sulit.

Oleh karena itu, dengan memanfaatkan fasilitas-fasilitas yang diberikan komputer, perumusan-perumusan gelombang elektromagnetik yang abstrak akan lebih mudah dipahami. Visualisasi dari grafiknya dapat memberikan kemudahan bagi mahasiswa untuk lebih memahami materi yang diberikan.

Gelombang didefinisikan sebagai gangguan yang menjalar dalam suatu medium. Yang dimaksud medium adalah sekumpulan benda yang berinteraksi dimana gangguan itu menjalar. Jika dua gelombang menjalar dalam suatu medium, maka gangguan total pada medium adalah jumlah gangguan oelh masing-masing gelombang. Sifat ini disebut prinsip superposisi. Secara matematis dituliskan sebagai berikut:

Misalnya tiga buah gelombang dalam suatu medium yang simpangan masing-masing gelombangnya dinyatakan oleh:

$\mathrm{y}_{1}(\mathrm{x}, \mathrm{t}) ; \mathrm{y}_{2}(\mathrm{x}, \mathrm{t})$ dan $\mathrm{y}_{3}(\mathrm{x}, \mathrm{t})$

maka menurut prinsip superposisi, gelombang total $\mathrm{y}_{1}(\mathrm{x}, \mathrm{t})$ dari ketiga gelombang tersebut adalah $\mathrm{y}_{1}(\mathrm{x}, \mathrm{t})=\mathrm{y}_{1}(\mathrm{x}, \mathrm{t})+\mathrm{y}_{2}(\mathrm{x}, \mathrm{t})+$ $\mathrm{y}_{3}(\mathrm{x}, \mathrm{t})$

Pada kedua gelombang sinus dengan frekuensi dan amplitudo yang sama menjalar pada arah yang sama dengan kecepatan, serta fungsi gelombangnya dinyatakan oleh :

$$
\begin{aligned}
& \mathrm{y}_{1}=\mathrm{A} \sin (\mathrm{kx}-\omega \mathrm{t}) \\
& \mathrm{y}_{2}=\mathrm{A} \sin (\mathrm{kx}-\omega \mathrm{t})
\end{aligned}
$$

Sehingga hasil superposisinya :

$$
\mathrm{Y}=\mathrm{y}_{1}+\mathrm{y}_{2}=\mathrm{A}[\sin (\mathrm{kx}-\omega \mathrm{t})+\sin (\mathrm{kx}-\omega \mathrm{t})]
$$

Dari rumus

$\sin \mathrm{B}+\sin \mathrm{C}=2 \sin 1 / 2(\mathrm{~B}+\mathrm{C}) \cos 1 / 2(\mathrm{~B}-\mathrm{C})$

Maka diperoleh $\mathrm{y}=2 \mathrm{~A} \sin (\mathrm{kx}-\omega \mathrm{t})$

Dua gelombang sinus dengan frekuensi dan amplitudo yang sama, menjalar pada arah dan kecepatan yang sama pula akan tetapi mempunyai fase yang berlainan. Fungsi gelombang untuk kedua gelombang dinyatakan oleh:

$$
\begin{aligned}
& \mathrm{y}_{1}=A \sin (\mathrm{kx}-\omega \mathrm{t}) \\
& \mathrm{y}_{2}=\mathrm{A} \sin \left(\mathrm{kx}-\omega \mathrm{t}-\theta_{1}\right)
\end{aligned}
$$

Hasil superposisi dari dua gelombang tersebut adalah sebagai berikut :

$$
\mathrm{Y}=\mathrm{y}_{1}+\mathrm{y}_{2}=\mathrm{A}\left\{\sin (\mathrm{kx}-\omega \mathrm{t})+\sin \left(\mathrm{kx}-\omega \mathrm{t}-\theta_{1}\right)\right\}
$$

Microsoft excel adalah program aplikasi spreadsheet yang paling populer dan paling banyak digunakan saat ini, yang akan membantu dalam menghitung, memproyeksikan, menganalisa dan mempresentasikan data. Simulasi dengan menggunakan spreadsheet excel menyajikan simulasi osilasi harmonik sederhana dan simulasi osilasi harmonik teredam dapat mengurangi terjadinya miskonsepsi konsep yang abstrak (Putri 
dan Pujayanto, 2015). Fasilitas spreadsheet juga dapat diimplementasikan dalam analisis numerik pada persamaan diferensial, persamaan gelombang dan persamaan laplace (Lau, 2016). Beberapa materi yang bisa diselesaikan dengan memanfaatkan spreadsheet excel di dalam model matematika antara lain limit (Jan and Sona, 2017). Kemampuan berkomunikasi ilmiah juga meningkat dengan menggunakan bahan ajar SMA berbasis spreadsheet (Sutardi, 2010).

Kemampuan spreadsheet excel dapat juga memecahkan masalah persamaan gelombang elektromagnetik yang sulit dimengerti makna fisisnya jika hanya dilihat rumusnya saja, dengan memanfaatkan fasilitas grafik di spreadsheet maka rumusan gelombang dapat mudah dipahami makna fisisnya (Lau and Kuruganty, 2010). Selain itu, pendekatan yang menekankan pada pengalaman berbasiskan spreadsheet memudahkan guru memaknai generalisasi serta mengapresiasi kreasi penambahan sejumlah konsep dengan tingkat abstraksi yang juga meningkat (I Nyoman, 2010).

\section{METODE PENELITIAN}

Metode penelitian yang digunakan adalah metode kuantitatif, dilakukan dua tahapan penelitian. Penelitian ini merupakan simulasi dari variabel amplitudo dan frekuensi gelombang, sehingga kita peroleh visualisasi grafis perlayangan gelombang.

Penelitian ini dilaksanakan dalam dua tahapan, tahapan yang pertama dimulai dari studi pustaka pendukung terutama yang berkaitan dengan superposisi gelombang. Langkah selanjutnya adalah menurunkan rumusan superposisi dua gelombang dengan variasi frekuensi, amplitudo, dan fase yang berbeda-beda. Berdasarkan rumus tersebut dibuat data sintetik berupa runtun waktu yang merupakan ungkapan simpangan

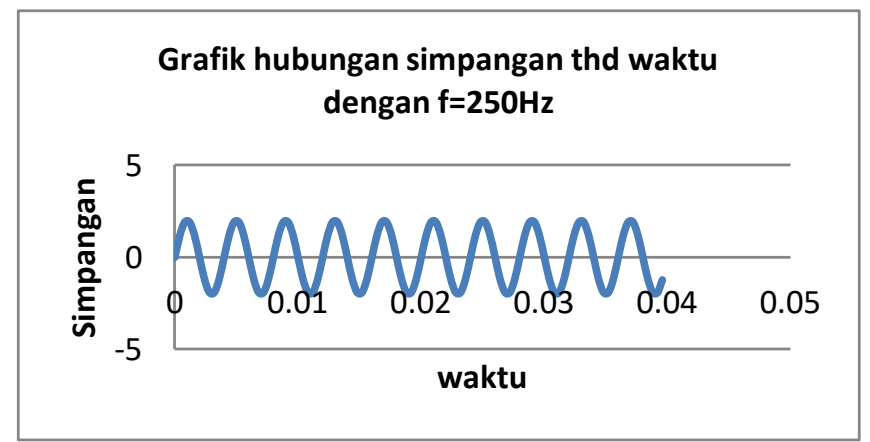

Gambar 1. Garfik Hubungan Simpangan vs Waktu dengan $\mathrm{f}=250 \mathrm{~Hz}$

sebagai fungsi waktu. Selanjutnya divisualisasikan dalam bentuk grafik. Tahapan kedua yang dilakukan hampir sama dengan tahapan pertama yaitu studi pustaka, namun cukup dengan memperoleh fungsi gelombang tunggal.

\section{HASIL DAN PEMBAHASAN}

Untuk melukiskan bentuk gelombang dalam Ms. Excel, terlebih dahulu ditentukan frekuensi gelombang, kemudian ditentukan pula frekuensi cuplikannya. Patokan frekuensi cuplikan yang digunakan besarnya adalah sama atau lebih besar dari 10 kali frekuensi gelombang. Sebagai contoh gelombang yang hendak dilukis memiliki frekuensi $250 \mathrm{~Hz}$, maka frekuensi cuplikan minimal $2500 \mathrm{~Hz}$ yang artinya setiap detiknya terdapat minimal 2500 data. Dengan frekuensi cuplikan ini akan ada 10 data setiap panjang gelombang.

Gambar 1 Visualisasi gelombang yang memiliki frekuensi 250 $\mathrm{Hz}$ dengan frekuensi cuplikan $2500 \mathrm{~Hz}$ dengan amplitudo 2 satuan selama 0,04 detik

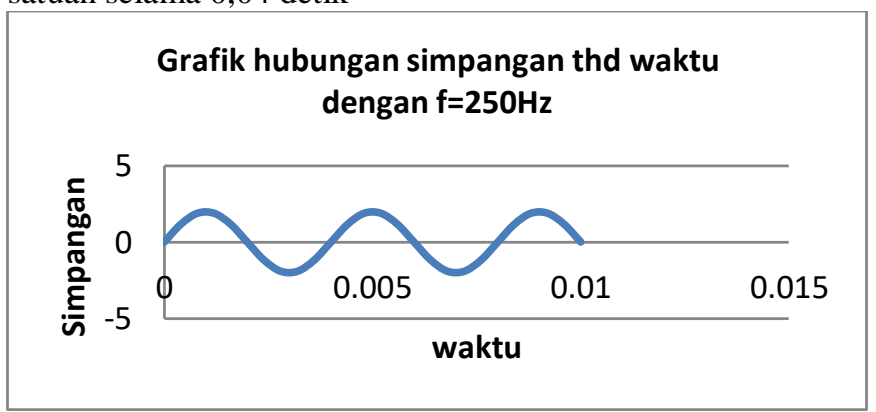

Gambar 2. Garfik Hubungan Simpangan vs Waktu dengan f cuplikan $2500 \mathrm{~Hz}$ Amplitudo 2 selama 0,01 detik

Gambar 2 Visualisasi gelombang yang memiliki frekuensi 250 $\mathrm{Hz}$ dengan frekuensi cuplikan $2500 \mathrm{~Hz}$ dengan amplitudo 2 satuan selama 0,01 detik

Gambar 5.1 menunjukkan visualisasi gelombang dengan frekuensi $250 \mathrm{~Hz}$ yang dihasilkan berdasarkan data sintetik menggunakan frekuensi cuplikan $2500 \mathrm{~Hz}$ dan menggambarkan bentuk gelombang sinus secara keseluruhan dengan amplitudo 2 satuan dalam selang waktu 0,04 detik. Gambar 5.2 merupakan cuplikan dari visualisasi gelombang dalam selang waktu 0,01 detik dihasilkan 2,5 panjang gelombang dengan 10 data setiap satu panjang gelombang.

Superposisi dua gelombang yang menjalar pada suatu medium dengan kecepatan serta fase yang sama tetapi memiliki selisih frekuensi yang kecil akan menghasilkan perlayangan gelombang dengan besarnya frekuensi perlayangan adalah selisih frekuensi antara gelombang tersebut. Misal dua gelombang memiliki amplitudo sama yaitu 2 satuan, dan frekuensi masing-masing $250 \mathrm{~Hz}$ dan $252 \mathrm{~Hz}$ disuperposisikan akan dihasilkan grafik seperti tampak pada gambar 3 .

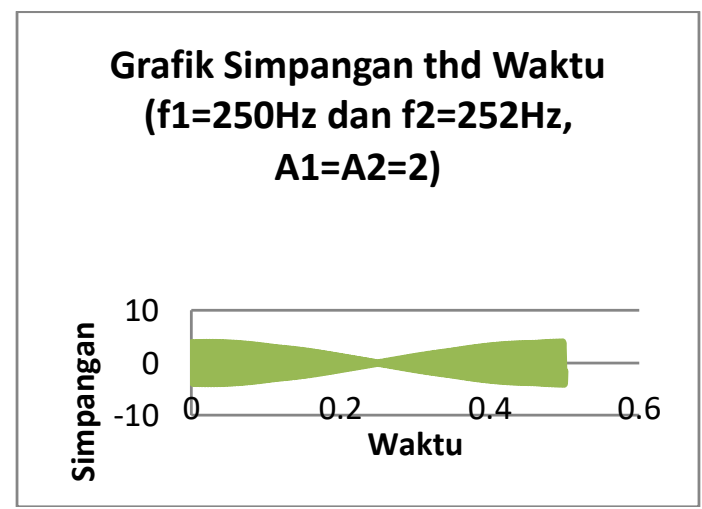


Gambar 3. Pola perlayangan gelombang berdasarkan superposisi gelombang secara analitik dan dengan spreadsheet excel

Dari gambar 3 dapat dilihat bahwa selama rentang waktu 2 detik terdapat 2 gelombang modulasi sehingga dengan demikian besarnya frekuensi modulasinya adalah $1 \mathrm{~Hz}$ atau dalam 1 detik terdapat 1 panjang gelombang. Ini berarti frekuensi perlayangan adalah $2 \mathrm{~Hz}$ yang tidak lain adalah selisih frekuensi antara dua gelombang yang dijumlahkan. Perlayangan gelombang sebagai hasil superposisi dua gelombang seperti gambar 5.3 secara analitik dan menggunakan spreadsheet excel memiliki pola yang sama. Besarnya simpangan gelombang modulasinya setara dengan persamaan $Y=2 A \cos \left(2 \pi\left(\frac{1}{2} \Delta f\right) t\right)$, ini berarti bahwa amplitudo gelombang hasil superposisi berubah terhadap waktu dengan frekuensi modulasi $\frac{1}{2} \Delta f$. Ketika nilai $\cos \left(2 \pi\left(\frac{1}{2} \Delta f\right) t\right) \sim \cos 90^{\circ}$, maka simpangannya bernilai minimal yaitu nol.

\subsection{Pengaruh Amplitudo terhadap Perlayangan Gelombang}

Konsep perlayangan gelombang yang diajarkan biasanya merupakan hasil superposisi dua gelombang yang memiliki amplitudo sama dan tidak pernah dijumpai perlayangan gelombang dengan amplitudo gelombang yang berbeda. Oleh karen itu, peneliti mencoba membuat grafik dengan amplitudo yang berbeda. Pada pembuatan grafik ini, nilai amplitudo gelombang pertama $A_{1}=2$ satuan dan amplitudo kedua $A_{2}=4$ satuan, besarnya frekuensi gelombang pertama $f_{1}=250 \mathrm{~Hz}$ dan frekuensi gelombang kedua $\mathrm{f}_{2}=252 \mathrm{~Hz}$, akan diperoleh grafik sebagai berikut :

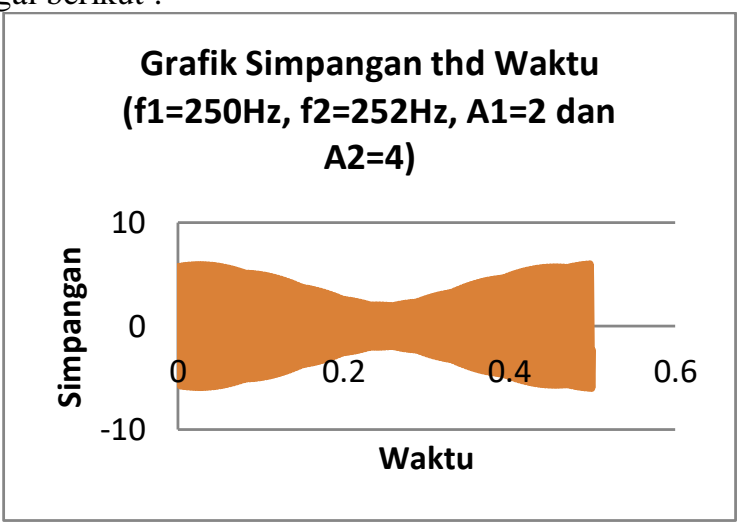

Gambar 4. Pola perlayangan gelombang berdasarkan superposisi gelombang secara analitik dan dengan spreadsheet excel dengan nilai amplitudo kedua gelombang masing-masing 2 dan 4 satuan

\subsection{Pengaruh Beda Fase terhadap Perlayangan Gelombang}

Pada pembuatan grafik ini, diamati dalm keadaan amplitudo yang sama dan dalam amplitudo yang berbeda, tetapi antara kedua gelombang yang dijumlahkan memiliki beda fase sebesar $\frac{\pi}{4}$ radian. Dengan harga frekuensi gelombang pertama
$250 \mathrm{~Hz}$ dan frekuensi gelombang kedua $252 \mathrm{~Hz}$, akan diperoleh grafik sebagai berikut :

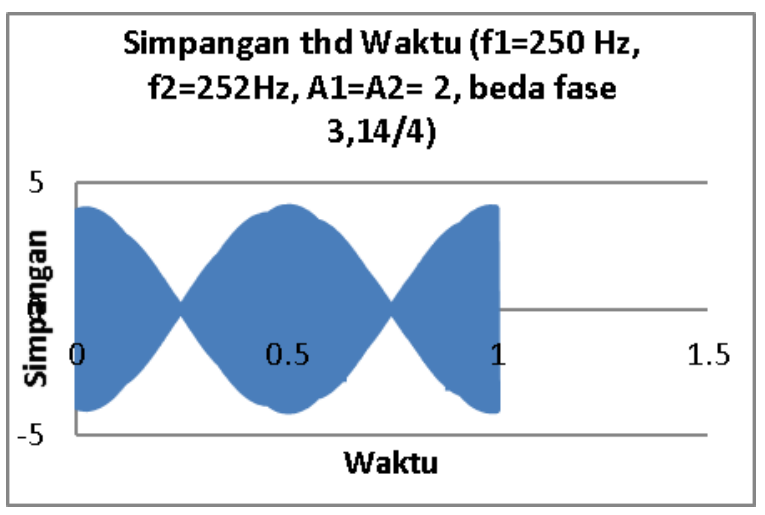

Gambar 5. Pola perlayangan gelombang berdasarkan superposisi gelombang secara analitik dan dengan spreadsheet excel dengan beda fase $\frac{\pi}{4}$ radian dan amplitudo sama

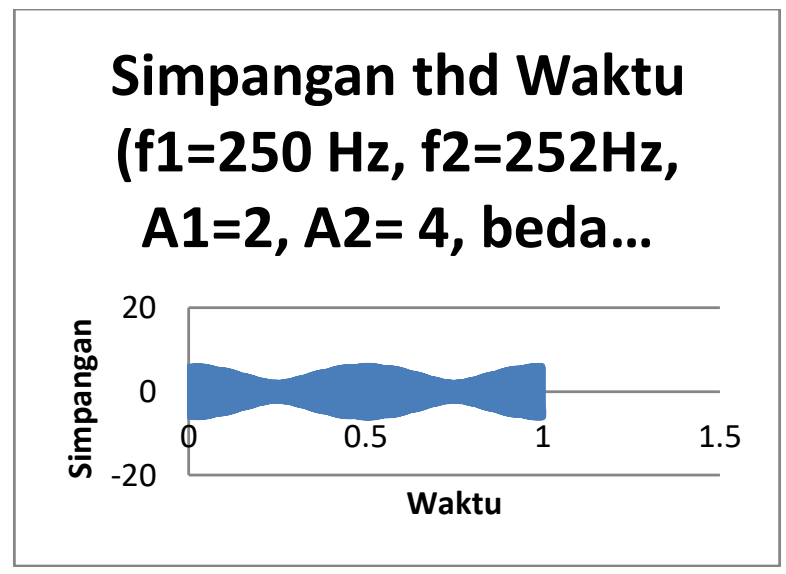

Gambar 6. Pola perlayangan gelombang berdasarkan superposisi gelombang secara analitik dan dengan spreadsheet excel dengan beda fase $\frac{\pi}{4}$ radian dan amplitudo $\mathrm{A}_{1}=2$ satuan dan $\mathrm{A}_{2}=4$ satuan

Dari grafik yang diperoleh ditunjukkan bahwa frekuensi modulasi yang dihasilkan adalah $1 \mathrm{~Hz}$ yang artinya dalam 1 detik terdapat satu panjang gelombang, sehingga frekuensi perlayangannya $2 \mathrm{~Hz}$. Adanya beda fase sebesar $\frac{\pi}{4}$ radian menyebabkan gelombang kedua bergerak lebih dahulu ke arah sumbu $\mathrm{x}$ ke kiri dibanding gelombang yang pertama, sehingga secara keseluruhan hasil superposisi kedua gelombang tersebut menghasilkan gelombang yang mengalami pergeseran sebesar $\frac{\pi}{8}$ radian.

\section{KESIMPULAN}

Dari penelitian yang telah dilakukan, diperoleh kesimpulan: Memvisualisasikan konsep perlayangan gelombang dengan bantuan spreadsheet excel lebih mudah dibandingkan secara analitik, karena dengan memanfaatkan fasilitas yang ada pada 
excel langsung bisa diperoleh visualisasi perlayangan gelombang tanpa harus menurunkan persamaannya terlebih dahulu. Perlayangan gelombang tidak tergantung pada besarnya amplitudo dan beda fase.

\section{DAFTAR PUSTAKA}

Connery, K.F. 2007. Graphing Predictions Enhancing Higher Order Thinking Skills in Science and Mathematics. Washington: National Academy Press.

I Nyoman, S. 2010. Mempelajari Konsep Matematika yang Tersembunyi pada Tabel Perkalian melalui Spreadsheet. JPTK UNDIKSHA. Vol.7(1).1-12.

Jan, B., and Sona, C. 2017. Free Fall in Vacuum and in the AirCalculating Limits Using a Real Example and Demonstrating the Limiting Process to High School Students Using Excel. Electric Journal Spreadsheet in Education. Vol 9(3). 1-13.

Lau, M.A., dan Kuruganty, S.P. 2010. Spreadsheet Implementations for Solving Boundary-Value Problems in Electromagnetics. Electric Journal Spreadsheet in Education. Vol. 4(1). 1-18.

Lau, M.A. 2016. Spreadsheet Implementation of Numerical and Analytical Solutions to Some Classical Partial Differential Equations. Electric Journal Spreadsheet in Education. Vol. 9(1). 1-45.

Putri, S., dan Pujayanto. 2015. Media Pembelajaran Menggunakan Spreadsheet Excel untuk Materi Osilasi Harmonik Teredam. Prosiding SNFPF. Vol 6(1). 263269

Sudjana N. dan A. Rifai. 2007. Teknologi Pengajaran. Bandung: Sinar Baru Algesindo Offset.

Sutardi. 2010. Pengembangan Bahan Ajar Fisika SMA Berbasis Spreadsheet untuk Meningkatkan Kemampuan Siswa Berkomunikasi Ilmiah. Prosiding Pertemuan Ilmiah XXIV HFI Jateng. 168-179.

Tjia M.O. 1994. Gelombang. Solo: Dabara Publisher. 